\title{
IN VITRO DNA REPLICATION OF PLASMID pKYM
}

\author{
TETSU HASE, $^{\dagger}$ MAKOTO WATANABE, HIROO YASUKAWA, \\ AND YUKITO MASAMUNE* \\ Department of Microbiology, Faculty of Pharmaceutical Sciences, Kanazawa University, \\ 13-1 Takara-machi, Kanazawa 920, Japan
}

(Received June 8, 1992)

\begin{abstract}
DNA of plasmid pKYM replicates in the extract prepared following the method of Fuller et al. (Fuller, R. S., Kaguni, J. M., and Kornberg, A. (1981) Proc. Natl. Acad. Sci. USA, 78, 7370-7374), when it contains the Rep protein of pKYM. Although the synthesis of DNA was completely inhibited by the DNA gyrase inhibitor, a substantial quantity of DNA was synthesized even in the absence of RNA synthesis and the accumulated DNA contained a strand-specific single-stranded circular molecule. The kinetic analysis of the DNA synthesis in the absence of RNA synthesis suggests that the single-stranded DNA appeared after the synthesis of double-stranded molecule. Since the DNA synthesized under the condition which allowed the synthesis of RNA is a fully twisted doublestranded molecule, the synthesis of RNA will initiate the DNA synthesis on the single-stranded molecule. These results support the idea that pKYM replicates via a rolling-circle mechanism.
\end{abstract}

Plasmid pKYM isolated from Shigella sonnei, a Gram-negative bacterium, is a tiny multicopy plasmid and encodes a Rep protein that is essential for its replication (20). A comparison of the protein to those encoded by other plasmids shows that it has a homology to the Rep proteins of the pUB110 plasmid family of Grampositive bacteria. The nucleotide sequences at the replication origins of $\mathrm{pKYM}$ and pUB110 plasmid family also have a consensus sequence, 5'CTTAaggGATAaaT (underlined sequence; 23). These results suggest that pKYM belongs to the pUB110 plasmid family. The plasmids of Gram-positive bacteria replicate, generally, via a rolling-circle mechanism $(16,17)$. Since the strand-specific single-stranded circular DNA of pKYM was recovered in vivo, we proposed that $\mathrm{pKYM}$ replicated via a rolling-circle mechanism (23). We have developed an in vitro replication system where DNA of pKYM replicated specifically (18). Using this system, we

* Address reprint request to: Dr. Yukito Masamune, Department of Microbiology, Faculty of Pharmaceutical Sciences, Kanazawa University, 13-1 Takara-machi, Kanazawa 920, Japan.

† Present address: Nasu Laboratory, Eiken Chemical Co., Ltd., Otawara 329-26, Japan. 
have examined the replication mechanism of pKYM and confirmed that pKYM replicated via a rolling-circle mechanism.

\section{MATERIALS AND METHODS}

Bacteria, plasmids and phages. Escherichia coli (E. coli) YS1 (19) carrying pOPM3701 was used to prepare the extracts. E. coli JM109(22) was used to prepare the derivatives of phage M13. pBR322-pKYM is a hybrid plasmid of pKYM and pBR322(20). pOPM3701 is a derivative of pBR322 carrying the rep gene of pKYM under the control of $\lambda \mathrm{cI}^{\mathrm{t} 8557}$ as described in the previous paper (18). M13-Plus carries the EcoRI (nucleotide number 804)-SphI (1979) fragment (1,175 bases). The numbering of nucleotide is shown in the previous paper (11). Plus means the coding strand of rep gene (11). This phage is used to prepare the probe to detect plus strand of pKYM as shown in the section of "Southern blot hybridization." M13-Minus carries the same EcoRI-SphI fragment of the opposite strand to M13-Plus and is used to detect minus-strand of pKYM.

Preparation of extract. E. coli YS1 (pOPM3701) was grown to $2 \times 10^{8} \mathrm{cells} / \mathrm{ml}$ in PBB broth (18) at $27^{\circ} \mathrm{C}$. Then it was transferred to $42^{\circ} \mathrm{C}$ and further incubated for $2 \mathrm{~h}$. The cells were collected and the Fraction II of Fuller et al. (6), was prepared following the method as described in the previous paper (18). The Fraction II was frozen and kept in liquid nitrogen before use.

DNA replication in vitro. In vitro replication of plasmid DNA using Fraction II was carried out as described previously (18). The reaction mixture $(25 \mu \mathrm{l})$ contained 40 m M Hepes-KOH, pH 7.6, 2 m M ATP, 0.5 mM each of CTP, UTP and GTP, $1 \mu \mathrm{g}$ bovine serum albumin, $22 \mathrm{mM}$ creatine phosphate, $11 \mathrm{mM}$ magnesium acetate, $2.5 \mu \mathrm{g}$ creatine kinase, $4.8 \%$ polyvinyl alcohol (w/v), $48 \mu \mathrm{M}$ each of dATP, dGTP, dTTP and dCTP, $0.4 \mu \mathrm{g}$ of covalently closed circular template DNA and 2 $\mu \mathrm{l}$ of Fraction II (220-370 $\mu \mathrm{g}$ of protein). ${ }^{32} \mathrm{P}$-labeled DNA was synthesized using $\left[\alpha^{-32} \mathrm{P}\right] \mathrm{dCTP}\left(1.0 \times 10^{4} \mathrm{cpm} / \mathrm{pmol}\right)$ as a labeled substrate and used to analyze the DNA in agarose gel electrophoresis. The reaction mixture was incubated at $30^{\circ} \mathrm{C}$ for $30 \mathrm{~min}$, except noted otherwise; the reaction was stopped by adding $5 \mu$ l mixture of $2.5 \% \mathrm{SDS}-0.25 \mathrm{M}$ EDTA. After the treatment with proteinase $\mathrm{K}$, samples were extracted with phenol/chloroform mixture $(1: 1)$. DNA was recovered by alcohol precipitation. Samples were analyzed by electrophoresis through $1.2 \%$ agarose gel using $40 \mathrm{~mm}$ Tris acetate $/ 1 \mathrm{~mm}$ EDTA buffer containing $0.3 \mu \mathrm{g} / \mathrm{ml}$ ethidium bromide. In the presence of ethidium bromide, open circular DNA, closed circular twisted DNA and single-stranded DNA of pKYM were well saparated $(13,14)$. The extent of DNA synthesis in the reaction was determined by measuring the trichloroacetic acid precipitable radioactivity, using [methyl- ${ }^{3} \mathrm{H}$ ] dTTP $(80 \mathrm{cpm} /$ pmol) as a labeled substrate (20). Unlabeled replication products were analyzed by Southern blot hybridization as described below.

Southern blot hybridization. DNA was transferred from agarose gels before or after denaturation (14) to nitrocellulose filter (Schleicher \& Schuell) by using $6 \times$ 
$\mathrm{NaCl} /$ sodium citrate $(1 \times \mathrm{NaCl} /$ sodium citrate is $0.15 \mathrm{M} \mathrm{NaCl} / 0.015 \mathrm{~m}$ sodium citrate) as described previously (23). Hybridization using ${ }^{32} \mathrm{P}$-labeled probes was carried out at $42^{\circ} \mathrm{C}$ in $6 \times \mathrm{NaCl} /$ sodium citrate, and filters were washed and exposed to X-ray films (16). Positions of various forms of DNA were identified by UV photography prior to the transfer of DNA.

${ }^{32}$ P-labeled DNA probe of pKYM was synthesized with "Random Primer DNA Labeling Kit" (Takara Shuzo Co., Ltd.) using pKYM as template in the presence of $\left[\alpha^{32} \mathrm{P}\right] \mathrm{dCTP}$ as described (23). Probes to detect the plus- and minus-strand of pKYM were synthesized with the kit using M13-Plus and M13Minus DNA as templates, respectively.

Enzymes, nucleotides and other methods. Restriction enzymes were purchased from Toyobo Co., Ltd. and Takara Shuzo Co., Ltd. Exonuclease VII (4) and Sl endonuclease (1) were the products of Bethesda Research Laboratories. These enzymes were used following the instructions of suppliers. Bovine serum albumin and nalidixic acid were the products of Sigma Chemical Company. Proteinase $\mathrm{K}$ was the product of Merck. Creatine kinase, creatine phosphate, deoxyribonucleoside triphosphates, ribonucleoside triphosphates and rifampicin were the products of Boehringer Mannheim GmbH. The construction of the recombinant plasmids, and the transformation of the cells with these plasmids were performed following the methods described previously $(18,20,23)$. DNAs used as template were purified by twice equilibrium centrifugations in $\mathrm{CsCl}$-ethidium bromide.

\section{RESULTS}

\section{Synthesis of $p K Y M D N A$ in vitro}

As shown in Table 1A, the plasmids carrying the replication origin of $\mathrm{pKYM}$ replicated specifically with the Fraction II prepared from the cells containing the Rep protein of pKYM following the method described in "Materials and Methods."

Table 1. DNA replication in vitro.

(A)

\begin{tabular}{|c|c|c|c|}
\hline \multicolumn{2}{|c|}{ Template specificity } & \multicolumn{2}{|c|}{ Requirements } \\
\hline & $\begin{array}{l}\text { dTMP incorporation } \\
(\text { pmol })\end{array}$ & & $\begin{array}{c}\text { Incorporation } \\
(\%)^{a}\end{array}$ \\
\hline pKYM & 32.5 & Complete & 100 \\
\hline pKYM-pBR322 & 27.9 & $-\mathrm{ATP}$ & 0 \\
\hline pBR322 & 0.6 & $-\mathrm{CTP},-\mathrm{GTP},-\mathrm{UTP}$ & 26 \\
\hline \multirow[t]{3}{*}{ No DNA } & 0.0 & + Rifampicin $(100 \mu \mathrm{g} / \mathrm{ml})$ & 27 \\
\hline & & + Novobiocin $(100 \mu \mathrm{g} / \mathrm{ml})$ & 2 \\
\hline & & + Nalidixic acid $(100 \mu \mathrm{g} / \mathrm{ml})$ & 5 \\
\hline
\end{tabular}

Assays were carried out as described in the "Materials and Methods."

a Hundred percent corresponds to $32.5 \mathrm{pmol}$ of dTMP, which corresponds to $15 \%$ of the template DNA. 
As shown in Table 1B, the synthesis of pKYM DNA was strongly suppressed by the addition of the inhibitors of DNA gyrase-novobiocin or nalidixic acid ( 8 , 9)-and the synthesis depended on ATP. Although the inhibition of RNA synthesis is known to suppress the initiation of DNA synthesis by inhibiting the primer RNA synthesis $(2,3,12,19)$, a small but significant amont of DNA was synthesized without the addition of 3rNTPs (UTP, CTP and GTP) or in the presence of rifampicin, an inhibitor of RNA polymerase (15).

\section{Conversion of CC molecule to SS form in the presence of DNA gyrase inhibitor}

The synthesis of DNA was strongly inhibited by the inhibitors of DNA gyrase $(8,9)$ as shown in Table 1B. We have examined the structure of template DNA after the incubation with these drugs by Southern blot hybridization. The result suggests that in the presence of noboviocin or nalidixic acid, template DNA was converted to the single-stranded form (Fig. 1A). Lane 3 of Fig. 1A shows that the template DNA was converted to a fast-moving DNA when it was incubated with Fraction II and ATP. Lanes 6 and 7 show that the template DNA was converted to the fast-moving DNA even in the presence of novobiocin or nalidixic acid. Since the fast-moving DNAs were transferred to the nitrocellulose filter without denaturation and were digested by $\mathrm{S} 1$ endonuclease, an enzyme specific for single-stranded DNA (1) (data not shown), these molecules will be the single-stranded molecule (SS DNA) (14). This SS DNA hybridized with both strands of pKYM DNA. The conversion is specific for the pKYM DNA, for pBR322 DNA was not converted to SS DNA under the same conditions (Fig. 1B lanes 4 and 8 ).

\section{DNA synthesized in the absence of $3 r N T P S$}

The DNA synthesized in the absence of 3rNTPs (UTP, CTP and GTP) or in the presence of rifampicin was analyzed by agarose gel electrophoresis (Fig. 2A). In addition to the closed circular DNA (CC DNA) and open circular DNA (OC DNA), SS DNA was produced when the synthesis of RNA was blocked (lanes 3 and 7). The SS DNA, however, was not produced when RNA synthesis was allowed (Fig. 2A lane 1). The SS DNA was not digested with $E$. coli exonuclease VII which specifically digested single-stranded linear molecule (4) (lanes 6 and 10) but it was digested with S1 nuclease (lanes 5 and 9) and was transferred to the nitrocellulose filter without denaturation (data not shown). It was, however, not digested with EcoRI (lanes 4 and 8). These results suggest that the SS DNA is circular. Since the SS DNA hybridized specifically with the M13-Plus probe (Fig. 2B), it was the plus-strand of pKYM.

Kinetic analysis of the DNA synthesized in the absence of 3rNTPS

Time course of the DNA replication was examined in the absence of 3rNTPs. After the preincubation of template DNA with the Fraction II at $30^{\circ} \mathrm{C}$ for $10 \mathrm{~min}$, DNA synthesis was started by the addition of ATP and 4dNTPs. The time course of the synthesis of labeled DNA was examined by the incorporation of $\left[\alpha-{ }^{32} \mathrm{P}\right]$ 
(A)

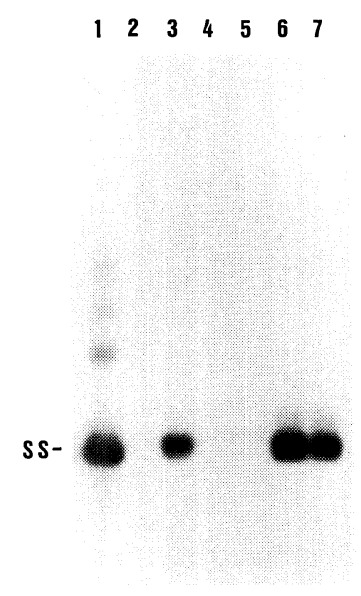

(B)

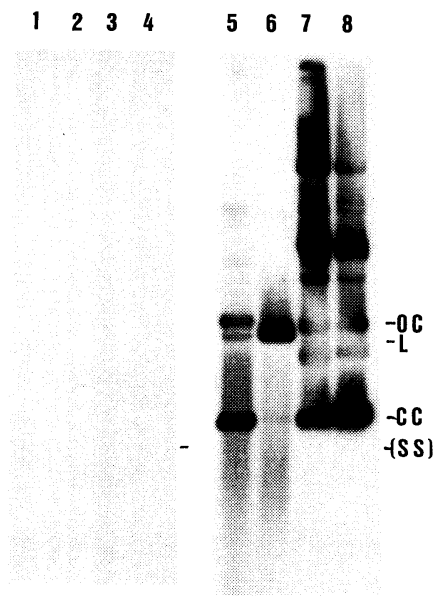

Fig. 1. Production of single-stranded DNA of pKYM by the incubation with Fraction II and ATP.

(A) pKYM DNA was incubated with Fraction II and ATP at $30^{\circ} \mathrm{C}$ for $10 \mathrm{~min}$. DNA was electrophoresed and transferred to nitrocellulose filter without prior denaturation. DNA-DNA hybridization was carried out using ${ }^{32} \mathrm{P}$-labeled pKYM DNA as a probe and autoradiographed as described in "Materials and Methods." Lane 1, SS DNA of pKYM; lane 2, DNA without incubation; lane 3, DNA incubated for $10 \mathrm{~min}$; lane 4, DNA incubated without ATP; lane 5, DNA incubated without Fraction II; lane 6, DNA incubated with Fraction II and ATP in the presence of novobiocin $(100 \mu \mathrm{g} / \mathrm{ml})$; lane 7 , DNA incubated with Fraction II and ATP in the presence of nalidixic acid $(100 \mu \mathrm{g} / \mathrm{ml})$. SS indicates the position of single-stranded DNA of pKYM.

(B) pBR322 DNA was incubated with Fraction II and ATP at $30^{\circ} \mathrm{C}$ for $10 \mathrm{~min}$ and analyzed as shown in (A) using ${ }^{32} \mathrm{P}$-labeled pBR322 DNA as a probe. Lanes 1 to 4 , samples transferred to the nitrocellulose membrane filter before denaturation; lanes 5 to 8 , samples transferred after denaturation. Lanes 1 and 5, pBR 322 DNA electrophoresed as a control; lanes 2 and 6, DNA digested with EcoRI; lanes 3 and 7, DNA mixed with Fraction II and ATP but not incubated; lanes 4 and 8, DNA incubated for $10 \mathrm{~min}$ with Fraction II and ATP. OC, L and CC indicate the position of open-circular, linear and closed circular DNAs of pBR322, respectively. (SS) indicates the expected position of single-stranded DNA of pBR322. Larger molecules than pKYM observed in lanes 7 and 8 are pOPM3701.

dCTP into DNA by an autoradiography (Fig. 3). The molecule labeled first was OC DNA, followed by CC molecule. SS DNA appeared lastly.

\section{DISCUSSION}

The analysis of the replication of plasmid pKYM in vivo suggests that it replicates via a rolling-circle mechanism (23), uncommon to the plasmid of Gram- 
(A)
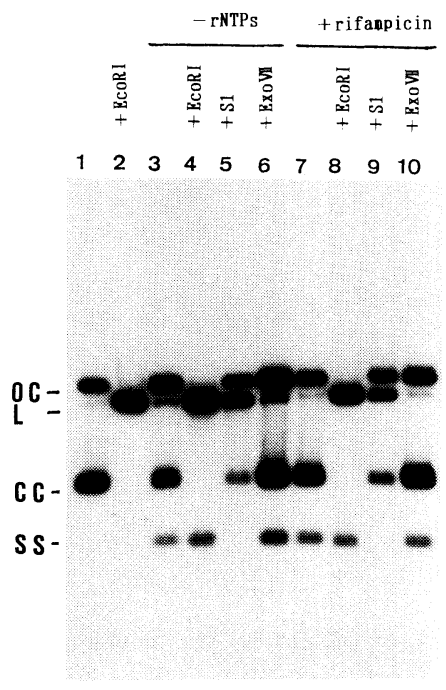

(B)
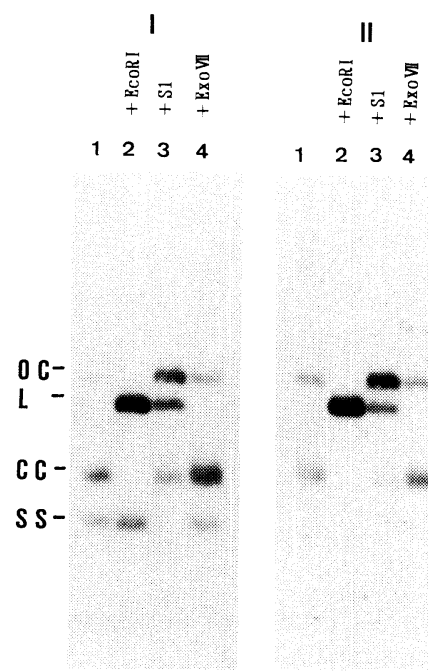

$\begin{array}{llll}1 & 2 & 3 & 4\end{array}$

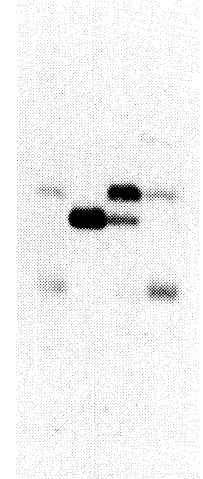

Fig. 2. The structures of DNA synthesized.

(A) The synthesis of single-stranded DNA in vitro. ${ }^{32} \mathrm{P}$-DNA synthesized at $30^{\circ} \mathrm{C}$ for $30 \mathrm{~min}$ was analyzed as described in Fig. 1. Lanes 1 and 2, DNA synthesized in the complete reaction mixture; lanes 3 to 6, DNA synthesized without 3rNTPs (UTP, CTP and GTP); lanes 7 to 10, DNA synthesized with rifampicin $(100 \mu \mathrm{g} / \mathrm{ml})$. Lanes 2, 4 and 8, the autoradiogram of the DNA electrophoresed after the digestion of EcoRI (4 units), lanes 5 and 9, those of the digest of S1 endonuclease ( 5 units), lanes 6 and 10 , those of the digest of exonuclease VII ( 5 units).

(B) Strand-specificity of the single-stranded DNA. (I) Hybridization with ${ }^{32} \mathrm{P}$ labeled probe specific to plus-strand. DNA synthesized without 3 rNTPs was transferred to nitrocellulose filter after denaturation and was hybridized with ${ }^{32} \mathrm{P}$. labeled probe prepared using M13-Plus. Lane 1, DNA synthesized without 3rNTPs; lane 2, DNA digested with EcoRI; lane 3, DNA digested with S1 endonuclease; lane 4, DNA digested with exonuclease VII. (II) Hybridization with the probe specific to minus-strand. The same experiments as above were performed using ${ }^{32} \mathrm{P}$-labeled probe prepared using M13-Minus. The samples in each lane were the same as those of (I). Symbols are the same as in Fig. 1.

negative bacteria. However, plasmids of Gram-positive bacteria generally replicate via a rolling-circle mechanism (17) and the plasmid pT181, a plasmid of Grampositive bacteria, was shown to replicate via a rolling-circle in vitro (16). We have established the in vitro replication system of the plasmid pKYM (20) and used the system to examine whether the plasmid replicated via a rolling-circle.

As shown in Table 1A, DNA synthesis was observed specifically with the template DNA containing the replication origin of $\mathrm{pKYM}$. The synthesis depended on the Rep protein of pKYM as shown previously (20). The addition of novobiocin or nalidixic acid strongly inhibited the synthesis. Sumida-Yasumoto et al. (21) and 
$\min \quad 00.5 \quad 1 \quad 2 \quad 4 \quad 6 \quad 8 \quad 10 \quad 1214 \quad 1618$

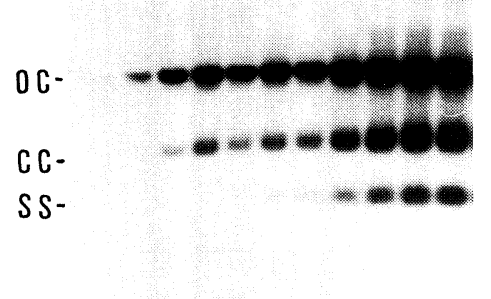

Fig. 3. Time course experiments of the DNA synthesis without 3rNTPs. The time course of the appearance of OC, CC, and SS DNA.

DNA syntheses without 3 rNTPs were examined by the incorporation of $\left[\alpha^{32} \mathrm{P}\right]$ dCTP. At the indicated times in the figure, samples were withdrawn and autoradiograph was taken after gel electrophoreses. Symbols are the same as in Fig. 1.

Hamatake et al. (10) reported that the in vitro replication of RF form of phage $\phi X-$ 174 which was known to replicate via a rolling-circle mechanism (5) was suppressed by these drugs. They suggested that the inhibition of DNA gyrase prevented the elongation of DNA. Our results show that the CC molecule of pKYM was converted to SS form by the incubation with Fraction II and ATP (Fig. 1A lane 3) and the conversion was not inhibited by these drugs (lanes 6 and 7). $\mathrm{CC}$ molecule of pBR322 was not converted to SS form under the same condition (Fig. 1B lanes 4 and 8 ). The conversion will require a single-strand break introduced by the Rep protein of pKYM. These results support the idea that the drugs inhibit the elongation of DNA, not the introduction of a single-strand break at the origin and the unwinding of the molecule (Fig. 4).

The DNA synthesized without the addition of 3rNTPs contained the strandspecific SS DNA, which was not observed when the synthesis was carried out in the presence of 3rNTPs (Figs. 2 and 3). The SS DNA will readily be converted to the double-stranded form by the synthesis initiated by RNA primer $(3,7)$.

The experiment to convert the SS DNA recoverd from agarose gel to the double-stranded form did not work and the original SS molecule was recovered. The SS DNA recovered will be contaminated with the inhibitor(s) of DNA synthesis.

We suggested in the previous in vitro experiment that $\mathrm{pKYM}$ would replicate via $\theta$ forms (18). The wrong conclusion was derived from the experiments where the syntheses of DNA were examined under the condition which allowed the synthesis of RNA, and our belief that the DNA gyrase would not be necessary for the rolling-circular replication.

When the synthesis of DNA was examined by the incorporation of labeled 


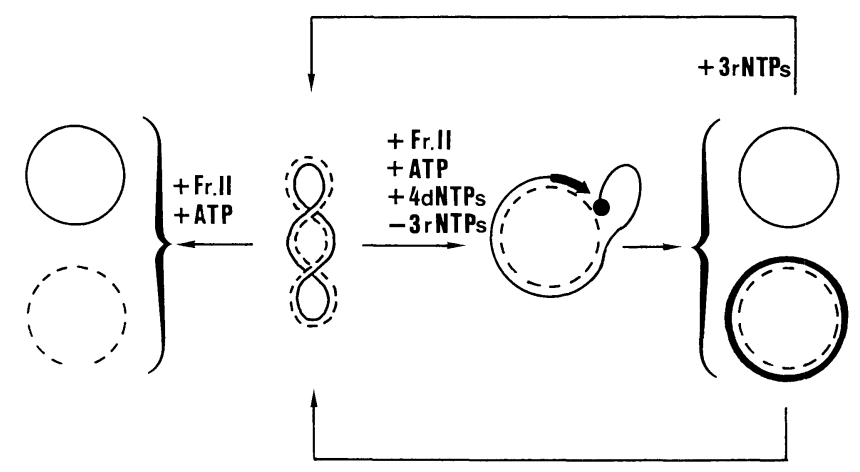

Fig. 4. Schematic representation of the replication of $\mathrm{pKYM}$ DNA.

A rolling-circle replication mechanism is shown following the scheme presented for $\phi X 174$ (3). Solid line represents the plus-strand (the coding strand of the Rep protein of pKYM). Dotted line is the minus-strand. Thick line is the newly synthesized DNA. Filled circle indicates the Rep protein of pKYM.

substrate, OC molecule appeared first and the production of $\mathrm{CC}$ molecule then followed, lastly SS molecule appeared (Fig. 3). The sequence is consistent with the scheme presented for the rolling-circle mechanism of DNA replication (Fig. 4) (5). The result also suggests that at least a second round of DNA replication occurred in this system, for the labeled SS DNA would not be produced at the first round replication by the rolling-circle mechanism. With this scheme, as the synthesis of plus-strand DNA will be initiated by using the $3^{\prime}$ end of the single-strand break introduced at the replication origin by the Rap protein, the plus-strand will be longer than the unit length. The preliminary experiment suggested the presence of such long molecules in the DNA synthesized in a short period of time (data not shown). These results are consistent with the scheme and support the idea that pKYM replicates via a rolling-circle mechanism.

\section{REFERENCES}

1) Ando, T., A nuclease specific for heat-denatured DNA isolated from a product of Aspergillus oryzae. Biochim. Biophys. Acta, 114, 158-168 (1966).

2) Arai, K. and Kornberg, A., A general priming system employing only $d n a B$ protein and primase for DNA replication. Proc. Natl. Acad. Sci. USA, 76, 4308-4312 (1979).

3) Brutlag, D., Schekman, R., and Kornberg, A., A possible role for RNA polymerase in the initiation of M13 DNA synthesis. Proc. Natl. Acad. Sci. USA, 68, 2826-2829 (1971).

4) Chase, J. W. and Richardson, C. C., Exonuclease VII of Escherichia coli. J. Biol. Chem., 249, 4545-4552 (1974).

5) Eisenberg, S., Scott, J. F., and Kornberg, A., Enzymatic replication of $\phi X 174$ duplex circles: Continuous synthesis. Cold Spring Harbor Symp. Quant. Biol., 43, 295-302 (1978).

6) Fuller, R. S., Kaguni, J. M., and Kornberg, A., Enzymatic replication of the origin of the Escherichia coli chromosome. Proc. Natl. Acad. Sci. USA, 78, 7370-7374 (1981).

7) Geider, K., Beck, E., and Schaller, H., An RNA transcribed from DNA at the origin of phage fd 
single strand to replicative form conversion. Proc. Natl. Acad. Sci. USA, 75, 645-649 (1978).

8) Gellert, M., Mizuuchi, K., O'dea, M. H., Itoh, T., and Tomizawa, J.-I., Nalidixic acid resistance: A second genetic character involved in DNA gyrase activity. Proc. Natl. Acad. Sci. USA, 74, 47724776 (1977).

9) Gellert, M., O’dea, M. H., Itoh, T., and Tomizawa, J.-I., Novobiocin and coumermycin inhibit DNA supercoiling catalyzed by DNA gyrase. Proc. Natl. Acad. Sci. USA, 73, 4474-4478 (1976).

10) Hamatake, R. K., Mukai, R., and Hayashi, M., Role of DNA gyrase subunit in synthesis of bacteriophage $\phi X 174$ viral DNA. Proc. Natl. Acad. Sci. USA, 78, 1532-1536 (1981).

11) Hirose, T., Hase, T., and Masamune, Y., Purasumido pK YM no zen'enkihairetsu to fukuseikaishi ryoiki (Total nucleotide sequence of plasmid pKYM and its replication origin) (in Japanese). Yakugaku Zasshi, 108, 886-893 (1988).

12) Inuzuka, M. and Helinski, D. R., Requirement of a plasmid-encoded protein for replication in vitro of plasmid R6K. Proc. Natl. Acad. Sci. USA, 75, 5381-5385 (1978).

13) Kikuchi, A. and Asai, K., Reverse gyrase - a topoisomerase which introduces positive superhelical turns into DNA. Nature, 309, 677-681 (1984).

14) Maniatis, T., Fritsch, E. F., and Sambrook, J., Molecular Cloning: A Laboratory Manual. Cold Spring Harbor Laboratory, Cold Spring Harbor, NY (1982), p. 97-148.

15) McClue, W. R. and Cech, C. L., On the mechanism of rifampicin inhibition of RNA synthesis. $J$. Biol. Chem., 253, 8949-8959 (1978).

16) Murray, R. W., Koepsel, R. R., and Kahn, S. A., Synthesis of single-stranded plasmid pT181 DNA in vitro. J. Biol. Chem., 264, 1051-1057 (1989).

17) Novick, R. P., Staphylococcal plasmids and their replication. Annu. Rev. Microbiol., 43, 537-565 (1989).

18) Okabe, H., Kitamura, R., Shibata, H., Hase, T., Nakanishi, Y., and Masamune, Y., Purasumido pKYM no in vitro fukusei (In vitro replication of plasmid pKYM) (in Japanese). Yakugaku Zasshi, 109, 582-591 (1989).

19) Sakakibara, Y. and Tomizawa, J.-I., Replication of colicin El plasmid DNA in cell extracts. Proc. Natl. Acad. Sci. USA, 71, 802-806 (1974).

20) Sugiura, S., Nakatani, S., Mizukami, Y., Hase, T., Hirokawa, H., and Masamune, Y., Characterization of a mini plasmid isolated from Shigella sonnei. J. Biochem., 96, 1193-1204 (1984).

21) Sumida-Yasumoto, C., Ikeda, J.-E., Benz, E., Marians, K. J., Vicuna, R., Surge, S., Zipursky, S. L., and Hurwitz, J., Replication of $\phi$ X174 DNA: In vitro synthesis of $\phi$ X RFI DNA and circular, single-stranded DNA. Cold Spring Harbor Symp. Quant. Biol., 43, 311-329 (1978).

22) Yanisch-Perron, C., Vieria, J., and Messing, J., Improved M13 phage cloning vectors and host strains: nucleotide sequences of the M13 mp18 and pUC19 vectors. Gene, 33, 103-119 (1985).

23) Yasukawa, H., Hase, T., Sakai, S., and Masamune, Y., Rolling-circle replication of the plasmid pKYM isolated from a Gram-negative bacterium. Proc. Natl. Acad Sci. USA, 88, 10282-10286 (1991). 